\title{
PENGARUH VARIETAS DAN TEKNIK PERBANYAKAN BIBIT TERHADAP KECEPATAN PERTUMBUHAN MATA TUNAS TANAMAN TEBU
}

\section{THE EFFECT OF VARIETY AND BUDDING METHODS ON THE GROWTH RATE OF SUGARCANE BUD}

\author{
Prasadhana Deka Sukoco ${ }^{1)}$, Tri Wardhani ${ }^{2)}$ dan Suslam Pratamaningtyas ${ }^{2)}$ \\ ${ }^{1)}$ Alumni Fakultas Pertanian Universitas Widyagama Malang \\ ${ }^{2)}$ Dosen Fakultas Pertanian Universitas Widyagama Malang \\ Email: gregoriussukoco@gmail.com
}

\begin{abstract}
ABSTRAK
Dalam pengolahan tebu menjadi gula dibutuhkan tanaman tebu yang berkualitas dan tanaman tebu yang berkualitas diperoleh dari bibit tebu yang berkualitas dan kuantitasnya mencukupi. Penelitian ini dilaksanakan untuk mengetahui pengaruh metode pembibitan tebu pada tiga varietas tebu. Penelitian dilakukan dengan menggunakan rancangan acak kelompok faktorial (RAK) Faktor pertama yaitu varietas (V) yang terdiri dari tiga varietas yang berbeda umur panennya, yaitu V1: varietas yang memiliki umur genjah (varietas PS 881); V2: varietas yang memiliki umur tengah (varietas PSJK 922); dan V3: varietas yang memiliki masa panen akhir (varietas Bulu Lawang). Faktor kedua adalah teknik perbanyakan bibit yang terdiri dari 3 level, yaitu T1 (single bud planting), T2 (bagal mata) dan T3 (bud set). Dari kedua faktor tersebut diperoleh 9 kombinasi perlakuan yang diulang sebanyak 3 kali. Interaksi perlakuan tidak berpengaruh nyata terhadap variabel yang diamati, tetapi teknik perbanyakan bibit berpengaruh nyata terhadap jumlah daun, luas daun dan kecepatan tumbuh tunas pada 15 HST, serta berpengaruh nyata terhadap diameter batang pada umur 29 HST.
\end{abstract}

Kata kunci: bibit tebu, perbanyakan tunas, varietas

\begin{abstract}
In the processing of sugarcane plant into sugar, it is required qualified sugarcane plants, and qualified ones surely can be obtained from qualified sugarcane buds cutting which in sufficient quantity. This research was conducted to determine the effect of sugarcane cutting buds method on three varieties of sugarcane. It was conducted using group randomized factorial design. The first factor was varieties $(V)$ which consisting of three different varieties of harvest age, namely V1: varieties with early harvest age (PS 881 variety); V2: varieties with middle harvest age (PSJK 922 variety); and V3: varieties that have a long harvest age (Bulu Lawang). The second factor was bud cutting methods consisting of three methods, namely T1 (single bud planting), T2 (bagal mata), and T3 (bud set). From these two factors, it is obtained 9 treatment combinations which were repeated 3 times. The treatment interaction did not significantly affect the observed variables, but bud cutting methods significantly affected the leaf number, leaf area and shoot growth rate at 15 HST, and significantly effect the stem diameter at 29 HST.
\end{abstract}

Keywords : sugarcane buds, variety 


\section{PENDAHULUAN}

Tebu merupakan bahan baku utama dalam industri gula menurut Rukmana (2015). Kecenderungan global industri gula menunjukkan produksi gula dunia dalam beberapa tahun terakhir meningkat. Dalam budidaya tanaman tebu, bibit merupakan salah satu modal (investasi) yang menentukan jumlah batang dan pertumbuhan selanjutnya hingga menjadi tebu giling beserta potensi gulanya. Teknik perbanyakan bibit tanaman tebu beragam di antaranya ialah bagal, rayungan, top stek, bud chip, dan kultur jaringan. Permasalahan yang menjadi obyek penelitian yaitu: (1) Dengan adanya perbedaan dari varietas dan teknik perbanyakan bibit, apakah kecepatan tumbuh dari mata tunas tebu mengalami perbedaan atau bahkan sebaliknya; (2) Apakah terdapat perbedaan dalam hal kecepatan pertumbuhan tunas dan pembentukan daun serta batang secara signifikan pada kombinasi perlakuan.

Tujuan penelitian ini adalah (1) Untuk mengetahui pengaruh interaksi varietas dan teknik perbanyakan bibit tebu terhadap ke- cepatan tumbuh mata tunas, (2) Untuk mengetahui kombinasi yang baik antara varietas dan teknik perbanyakan bibit sebagai bahan tanam yang diharapkan dapat meningkatkan produktivitas tebu, dan (3) Untuk mengetahui kecepatan tumbuh dan perkembangan mata tunas tebu.

\section{Prospek Industri Gula Berbasis Tebu}

Gula merupakan komoditas penting di pasar internasional dan komoditas strategis dalam perekonomian Indonesia. Pengembangan industri gula berbasis tebu memberikan banyak peluang usaha antara lain usaha pembibitan tanaman tebu, usaha memproduksi gula pasir dan gula merah, serta penganekaragaman (diversifikasi) produk hasil ikutan tanaman tebu.

\section{Morfologi Tanaman Tebu}

Morfologi tanaman tebu (Saccharum officinarum L.) adalah sebagai berikut:

Tebu termasuk tanaman berkeping satu (monocotyledonae) dan mempunyai sistem perakaran serabut dengan panjang mencapai $0,5-1,0 \mathrm{~m}$. 
Daun tebu berbentuk seperti pita dengan panjang mencapai 1-2 $\mathrm{m}$ dengan lebar 5-7 $\mathrm{cm}$. Tulang daun sejajar, di bagian tengahnya berlekuk (midrib) (Rukmana, 2015). Batang tanaman tebu mampu mencapai ketinggian antara 2-5 meter, dengan diameter batang mampu mencapai 3$5 \mathrm{~cm}$.

Bunga tanaman tebu tersusun dalam malai dan berbentuk piramida dengan panjang antara $50-80 \mathrm{~cm}$ (Rukmana, 2015). Buah dan Biji tanaman tebu menyerupai Biji padi, memiliki satu biji dengan besar lembaga sepertiga panjang biji. Biji tebu dapat ditanam di kebun percobaan untuk mendapatkan jenis baru yang lebih unggul dengan cara inseminasi (Rukmana, 2015).

Tanaman tebu sama halnya dengan tanaman lainnya yang mempunyai beberapa fase dalam pertumbuhannya. Fase pertumbuhan tebu dibagi menjadi 4 menurut Rukmana (2015) yaitu fase perkecambahan (germination phase), pertunasan (tillering phase), pemanjangan batang/ruas (grand growth phase), dan pematangan (maturity and ripening phase).
Menurut Ciptadi (2013), tanaman tebu mempunyai karakteristik antara lain:

1. Pola kemasakan

a) Masak Awal, mencapai masak optimal pada umur 8-10 bulan.

b) Masak Tengah mencapai masak optimal pada umur 10-12 bulan.

c) Masak Lambat mencapai masak optimal umur lebih dari 10 bulan

2. Persyaratan Tumbuh

Beberapa kondisi lingkungan yang diperlukan untuk mendukung pertumbuhan dan perkembangan tanaman tebu antara lain: curah hujan tahunan, penyinaran matahari, ratarata kecepatan angin

\section{Varietas Tebu Yang Sering Digunakan}

Varietas tebu menurut Rukmana (2015) dibagi menjadi 3 varietas yaitu Pasuruan (PS), Prof Station Oost Java (POJ), dan Bultenlandse Zaadrietsoorten (BZ). Dari varietas awal tersebut didapat varietas-varietas terbaru yang lebih unggul. 


\section{Teknik Perbanyakan Tebu}

Ada beberapa teknik perbanyakan bibit tanaman tebu seperti: stek pucuk, bagal, rayungan, single bud, bibit kultur jaringan, tiap-tiap jenis bibit mempunyai kelemahan dan kelebihannya masing-masing. beberapa teknik perbanyakan tanaman tebu

\section{Standar Bibit}

Standar benih tebu yang sehat berdasarkan Standar Nasional Indonesia (SNI) dengan kriteria serangan hama penggerek batang $<2 \%$ dari jumlah ruas, penggerek pucuk $<5 \%$ dari jumlah ruas, hama lain $<5 \%$, benih diusahakan tidak terserang penyakit sistemik seperti Ratoon Stunting Disease (RSD), mosaik, dan blendok. Persyaratan mutu benih tebu berpedoman pada Standar Operasional Prosedur (SOP) Pemeriksaan Kebun Sumber Benih Tebu (Saccharum officinarum) RSNI 181 tahun 204/pedum sertifikasi bibit tebu 2009.

Mata tunas atau cikal bakal dari tanaman tebu, umumnya bersifat dorman saat masih tertutupi pelepah daun tanaman tebu, namun mata tunas mulai tumbuh saat kondisi di sekelilingnya mendukung untuk pertumbuhannya. Pertumbuhan mata tunas ini tentunya dipengaruhi oleh beberapa faktor dengan adanya proses tertentu yang mengakibatkan mata tunas ini tumbuh dan menjadi suatu individu baru.

\section{Hipotesis}

Hipotesis penelitian ini adalah sebagai berikut:

Diduga terdapat interaksi nyata antara varietas dan teknik perbanyakan bibit terhadap kecepatan pertunasan, daya tumbuh tunas, jumlah anakan, lebar daun, diameter batang, dan tinggi tanaman.

\section{METODE PENELITIAN}

\section{Tempat dan Waktu Penelitian}

Penelitian dilakukan di Kebun Percobaan Pabrik Gula Kebon Agung yang berlokasi di Pakisaji Kabupaten Malang. Penelitian dilaksanakan pada tanggal 15 Januari sampai dengan 28 Februari 2017.

\footnotetext{
Alat dan Bahan

Alat penelitian meliputi mistar, polibag dengan ukuran $20 \mathrm{x}$
} 
$10 \mathrm{~cm}$, jaring kawat, timbangan digital, kertas label, gembor, kertas milimeter blok, jangka sorong dan alat tulis. Sementara bahan percobaan meliputi media tanam kompos (kotoran ayam), tanah dan pasir dengan perbandingan 1:1:1 bibit tebu dengan varietas PS 881 (masa awal), PSJK922 (masa tengah), BL (masa akhir), Seed Treatment Insektisida (Cruiser 350 FS), Zat Pengatur Tumbuh + Fungisida (Atonik), pupuk NPK, bagal mata 3, SBP dan Bud Set. dengan 3 ulangan masing-masing perlakuan.

\section{Metode Penelitian}

Penelitian dilaksanakan dengan menggunakan Rancangan Acak Kelompok Faktorial (RAK). Pengelompokan berdasarkan posisi mata tunas yang digunakan sebagai bahan penelitian. Penelitian ini disusun secara faktorial yang terdiri dari 2 faktor, yaitu varietas (V) terdiri dari 3 varietas yang berbeda menurut umur panennya:

- $\mathrm{V} 1$ = Masa panen awal (genjah) dengan varietas PS 881
- $\mathrm{V} 2=$ Masa panen tengah dengan varietas PSJK 922

- $\mathrm{V} 3$ = Masa panen akhir dengan varietas Bulu Lawang

Sedangkan faktor kedua teknik perbanyakan bibit yang terdiri dari 3 metode yaitu:

- $\quad \mathrm{T} 1=$ Single Bud Planting (SBP)

- $\mathrm{T} 2=$ Bagal mata 3

- $\mathrm{T} 3=$ Bud Set

\section{Pelaksanaan Penelitian}

Media tanam yang digunakan adalah tanah, pasir dan kompos dengan perbandingan $1: 1: 1$, dengan ketebalan $11 \mathrm{~cm}$ dari dasar polibag. Sedangkan persiapan bibit adalah sebagai berikut.

\section{Single Bud Planting (SBP)}

- Pemotongan tanaman tebu yang telah berumur 6-7 bulan

- Membersihkan bibit dari daun tebu dan seleksi mata tunas.

- Pengambilan mata tunas dengan mesin plong

- Dilakukan Hot Water Treatment (HWT) dengan cara merendam dengan air panas pada suhu \pm $51^{\circ} \mathrm{C}$ selama 30 menit, 
Selanjutnya potongan-potongan batang tebu ditiriskan, lalu dilakukan perendaman dengan menggunakan seed treatment insekticide (Cruiser 350 FS), zat pengatur tumbuh + Fungisida (Atonik) selama \pm 10 menit. ).

\section{Bagal mata 3}

- Pemotong tanaman tebu yang berumur 6-7 bulan

- Lalu dilakukan pembersihan daun tebu atau pengelentekan sekaligus dilakukan sortasi mata tunas

- Selanjutnya pembuatan bagal mata 3, dengan cara dipotongpotong batang tebu yang menyertakan 3 mata tunas atau ruas dalam tiap potongnya.

\section{Bud Set}

- Pemotongan batang tebu yang telah berumur 6-7 bulan setelah tanam.

3.4.1 Lalu batang tebu tersebut dibersihkan dari daun tebu sekaligus dilakukan sortasi, dan diplong dengan mesin plong, tiap potongannya terdapat 1 mata tunas.

\section{Penanaman}

Bibit tebu ditanam dengan cara ditutupi tanah tipis pada bagian atas bibit, dengan posisi mata tunas menghadap ke atas.

\section{Pemeliharaan}

Pemeliharaan

bibit mencangkup: Penyiraman dilakukan sehari dua kali yaitu pada pagi hari dan sore hari masing-masing sebanyak 450 ml. Pemupukan dilakukan pada saat bibit berumur 15, dan 44 Hari Setelah Tanam (HST) dengan larutan NPK 11 gram dilarutkan dalam 5,5 liter untuk 27 polibag, sehingga tiap polibag mendapat $204 \mathrm{ml}$ pupuk NPK.

\section{Variabel Pengamatan}

Pengamatan dilakukan dengan dua tahap yaitu:

Masa pertunasan, diamati saat berumur 1, 2, 3, dan 4 MST (minggu setelah tanam). Parameter pengamat tersebut meliputi presentase pertunasan (1 sampai 4 MST). Kecepatan tumbuh (pengamatan dengan menghitung bibit tebu yang telah mengalami pertumbuhan normal. pengamatan dilakukan 
setiap hari sampai hari ke-44, dan pengolahan data dilakukan setiap minggu).

Masa pertumbuhan vegetatif awal, saat tanaman berumur 5,6,7, sampai 8 mst. Parameter pengamatan meliputi tinggi tunas, diameter tunas, jumlah daun, luas daun, dan jumlah anakan.

Pengamatan Daya tumbuh tunas dan Kecepatan tumbuh tunas Variabel yang diamati adalah daya tumbuh tunas, pada umur 1, 2, 3, 4, 5 sampai 6 mst terhadap kecambah normal, dan kecepatan tumbuh tunas (KCT), diamati tiap minggu mulai dari awal pengamatan pada umur 1 , 2, 3, 4, 5 mst hingga akhir pengamatan berumur 6 MST (tiap minggu sekali). Adapun rumus untuk menghitung Daya Tumbuh Tunas (DTT), dan Kecepatan tumbuh mata tunas (KCT) sebagai berikut:

$$
\begin{aligned}
& \text { Daya tumbuh tunas }=\frac{\text { Jumlah tunas Normal }}{\text { Jurahlah Bibit Ditanam }} \times 100 \%
\end{aligned}
$$

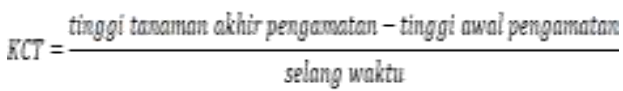

\section{Pengamatan Vegetatif}

Tinggi tunas $(\mathrm{cm})$ diukur dari atas permukaan tanah sampai titik tumbuh. Pengamatan dilakukan setiap satu minggu sekali, mulai berumur 1, 2, 3, 4, 5 sampai 6 MST. Jumlah daun (helai) dihitung secara keseluruhan dan diamati setiap satu minggu sekali mulai umur 1, 2, 3, 4, 5 sampai 6 MST.

Diameter batang diukur dari yang berdiameter besar dan diamati setiap satu minggu sekali mulai umur 1, 2, 3, 4, 5 sampai $6 \mathrm{MST}$.

Luas daun tanaman diamati mulai dari 10, 21, 32, 43 HST.

\section{Analisa Data}

Untuk mengetahui pengaruh perlakuan digunakan analisis ragam atau uji $F$, jika ada interaksi nyata untuk mengetahui perbedaan antara kombinasi perlakuan digunakan uji beda nyata jujur (BNJ) atau disebut juga uji Tukey dengan taraf kepercayaan 99\%. Kriterianya jika nilai $\mathrm{F}$ hitung lebih dari $\mathrm{F}$ tabel 0,05 dan 0,01 artinya perlakuan yang diuji memberikan pengaruhnya yang signifikan terhadap respon yang diamati. 


\section{HASIL DAN PEMBAHASAN}

\section{Daya Tumbuh Tunas}

Berdasarkan hasil analisa ragam untuk daya tumbuh tunas pada umur pengamatan 8 HST hingga 43 HST menunjukkan tidak ada interaksi antara teknik perbanyakan dan perbedaan varietas bibit terhadap daya tumbuh tunas.

Tabel 1. Daya Tumbuh Tunas Tanaman Tebu pada Perlakuan Perbanyakan Bibit (T) dan Varietas (V) pada Umur 8, 15, 22, 29, 36, dan 43 HST

\begin{tabular}{|c|c|c|c|c|c|c|}
\hline perlakuan & \multicolumn{6}{|c|}{ Daya Tumbuh Tunas } \\
\hline Varietas (V) & 8 & 15 & 22 & 29 & 36 & 43 \\
\hline V1 & $81,56 a$ & $89 a$ & $92,67 a$ & $92,67 a$ & $92,67 a$ & $92,67 a$ \\
\hline V2 & $63 a$ & $74,11 a$ & $74,11 a$ & $74,11 a$ & $74,11 a$ & $74,11 \mathrm{a}$ \\
\hline V3 & $59,22 a$ & $96,33 a$ & $96,33 a$ & $96,33 a$ & $96,33 a$ & $96,33 \mathrm{a}$ \\
\hline \multicolumn{7}{|c|}{ Teknik Perbanyakan (T) } \\
\hline $\mathrm{T} 1$ & $76,7 \mathrm{a}$ & $86,7 a$ & $86,7 \mathrm{a}$ & $86,7 \mathrm{a}$ & $86,7 \mathrm{a}$ & $86,7 a$ \\
\hline $\mathrm{T} 2$ & 45,88a & $83,5 a$ & $87,63 a$ & $87,63 a$ & 87,63 a & $87,63 \mathrm{a}$ \\
\hline $\mathrm{T} 3$ & $77,78 a$ & $88,89 a$ & $88,89 a$ & $88,89 a$ & $88,89 a$ & $88,89 a$ \\
\hline Keterang & $\begin{array}{l}\text { angk } \\
\text { uruf } \\
\text { ang } \\
\text { erbed }\end{array}$ & $\begin{array}{l}\text { a-angk } \\
\text { yang }\end{array}$ & ka yan & & $\mathrm{amp}$ & \\
\hline
\end{tabular}

\section{Kecepatan Tumbuh Tunas}

Berdasarkan hasil analisa ragam untuk kecepatan tumbuh tunas pada umur pengamatan 8 HST hingga 43 HST menunjukkan tidak adanya interaksi antar teknik perbanyakan dan perbedaan varietas bibit terhadap kecepatan tumbuh tunas.

Tabel 2. Kecepatan Tumbuh Tunas Tebu pada Perlakuan Varietas dan Teknik Pembuatan Bibit Pada Umur $8,15,22,29,36$, dan 43 HST (Hari Setelah Tanam)

\begin{tabular}{|c|c|c|c|c|c|c|}
\hline perlakuan & \multicolumn{7}{|c|}{ Kecepatan Tumbuh Tunas } \\
\hline Varietas (V) & 8 & 15 & 22 & 29 & 36 & 43 \\
\hline V1 & $0,14 a$ & $0,66 a$ & $0,53 a$ & $0,53 a$ & $0,61 a$ & $0,48 a$ \\
\hline V2 & $0,23 a$ & $0,47 a$ & $0,4 a$ & $0,5 a$ & $0,55 a$ & $0,4 a$ \\
\hline V3 & $0,16 a$ & $0,61 a$ & $0,47 a$ & $0,42 a$ & $0,5 a$ & $0,4 a$ \\
\hline Teknik Perbanyakan (T) & & & & & & \\
\hline T1 & $0,17 a$ & $0,55 a b$ & $0,47 a$ & $0,51 a$ & $0,53 a$ & $0,46 a$ \\
\hline T2 & $0,17 a$ & $0,71 b$ & $0,54 a$ & $0,57 a$ & $0,67 a$ & $0,46 a$ \\
\hline T3 & $0,18 a$ & $0,48 a$ & $0,38 a$ & $0,36 a$ & $0,47 a$ & $0,33 a$ \\
\hline
\end{tabular}

Keterangan : angka-angka yang di dampingi huruf yang sama pada kolom yang sama dinyatakan tidak berbeda nyata pada uji BNJ.

Dari data di atas dapat dilihat bahwa kecepatan tumbuh pada pengamatan ke 43 HST terlihat lebih kecil dibandingkan pengamatan sebelumnya

\section{Tinggi Tanaman}

Berdasarkan hasil analisa ragam untuk tinggi tanaman pada umur pengamatan 8 HST hingga 43 HST menunjukkan tidak adanya interaksi antar teknik perbanyakan dan perbedaan varietas bibit terhadap tinggi tanaman. Hasil yang tidak berbeda nyata dapat dilihat pada 
tabel 4.3 di mana tiap-tiap variabel tidak berpengaruh nyata terhadap tinggi tanaman.

Tabel 3. Tinggi Tanaman Tebu $(\mathrm{cm})$ pada Perlakuan Varietas dan Teknik Pembuatan Bibit pada Umur 8,15, 22, 29, 36, dan 43 HST (Hari Setelah Tanam)

\begin{tabular}{|c|c|c|c|c|c|c|}
\hline perlakuan & \multicolumn{7}{|c|}{ Tinggi Tanaman } \\
\hline Varietas (V) & 8 & 15 & 22 & 29 & 36 & 43 \\
\hline V1 & $1,12 a$ & $5,76 a$ & $9,14 a$ & $12,87 a$ & $15,1 a$ & $20,53 a$ \\
\hline V2 & $1,83 a$ & $5,1 a$ & $7,72 a$ & $11,21 a$ & $14,71 a$ & $17,51 a$ \\
\hline V3 & $1,24 a$ & $5,2 a$ & $8,48 a$ & $11,41 a$ & $14,93 a$ & $17,62 a$ \\
\hline Teknik Perbanyakan (T) & & & & & & \\
\hline T1 & $1,38 a$ & $5,26 a$ & $8,57 a$ & $12,13 a$ & $13,41 a$ & $18,7 a$ \\
\hline T2 & $1,33 a$ & $5,89 a$ & $9,4 a$ & $13,44 a$ & $18,11 a$ & $21,39 a$ \\
\hline T3 & $1,48 a$ & $4,88 a$ & $7,37 a$ & $9,92 a$ & $13,22 a$ & $15,57 a$ \\
\hline
\end{tabular}

Keterangan : angka-angka yang di dampingi huruf yang sama pada kolom yang sama dinyatakan tidak berbeda nyata pada uji $\mathrm{BNJ}$

\section{Jumlah Daun}

Berdasarkan hasil analisa ragam untuk jumlah daun pada umur pengamatan 21, 32, dan 43 HST menunjukkan tidak adanya interaksi antar teknik perbanyakan bibit dan perbedaan varietas bibit terhadap jumlah daun. Namun teknik perbanyakan bibit menunjukan adanya pengaruh nyata terhadap jumlah daun.
Tabel 4. Rata-Rata Jumlah Daun Tanaman Tebu (JD) Terhadap Perlakuan Perbedaan Varietas dan Teknik Perbanyakan Bibit Pada Umur Pengamatan 21, 32, dan 43 HST

\begin{tabular}{|c|c|c|c|}
\hline perlakuan & \multicolumn{3}{|c|}{ Jumlah Daun } \\
\hline Varietas (V) & 21 & 32 & 43 \\
\hline V1 & $3,67 \mathrm{a}$ & $5,22 \mathrm{a}$ & $6,44 \mathrm{a}$ \\
\hline V2 & $4,22 \mathrm{a}$ & $5,33 \mathrm{a}$ & $7,22 \mathrm{a}$ \\
\hline V3 & $4,22 \mathrm{a}$ & $6,33 \mathrm{a}$ & $7,44 \mathrm{a}$ \\
\hline Teknik Perbanyakan (T) & & & \\
\hline T1 & $2,0 \mathrm{a}$ & $3,22 \mathrm{a}$ & $4,0 \mathrm{a}$ \\
\hline T2 & $2,56 \mathrm{a}$ & $10,22 \mathrm{~b}$ & $4,1 \mathrm{a}$ \\
\hline T3 & $7,56 \mathrm{~b}$ & $3,44 \mathrm{a}$ & $13,0 \mathrm{~b}$ \\
\hline
\end{tabular}

Keterangan : angka-angka yang di dampingi huruf yang sama pada kolom yang sama dinyatakan tidak berbeda nyata pada uji BNJ

\section{Luas daun}

Berdasarkan hasil analisa ragam untuk luas daun pada umur pe-ngamatan 21, 32, dan 43 HST menunjukkan tidak adanya interaksi antar teknik perbanyakan bibit dan perbedaan varietas bibit terhadap luas daun tanaman tebu. Pengaruh nyata terlihat pada variabel teknik perbanyakan pada umur pengamatan 21, 32, dan 43HST. 
Tabel 5. Daun (LD) pada Perlakuan Perbedaan Varietas dan Teknik Perbanyakan Bibit pada Umur Pengamatan 21, 32, dan 43 HST

\begin{tabular}{|c|c|c|c|}
\hline perlakuan & \multicolumn{3}{|c|}{ Luas Daun } \\
\hline Varietas (V) & 21 & 32 & 43 \\
\hline V1 & $29,16 \mathrm{a}$ & $47,67 \mathrm{a}$ & $65,58 \mathrm{a}$ \\
\hline V2 & $28,68 \mathrm{a}$ & $42,6 \mathrm{a}$ & $53,54 \mathrm{a}$ \\
\hline V3 & $27,13 \mathrm{a}$ & $48,76 \mathrm{a}$ & $62,58 \mathrm{a}$ \\
\hline Teknik Perbanyakan (T) & & & \\
\hline T1 & $20,16 \mathrm{a}$ & $37,04 \mathrm{a}$ & $46,87 \mathrm{a}$ \\
\hline T2 & $25,16 \mathrm{ab}$ & $64,68 \mathrm{~b}$ & $85,93 \mathrm{~b}$ \\
\hline T3 & $39,65 \mathrm{~b}$ & $37,29 \mathrm{a}$ & $48,91 \mathrm{a}$ \\
\hline
\end{tabular}

Keterangan : angka-angka yang di dampingi huruf yang sama pada kolom yang sama dinyatakan tidak berbeda nyata pada uji BNJ

\section{Diameter Batang}

Berdasarkan hasil analisa ragam untuk diameter batang pada umur pengamatan 8 hingga 43 HST menunjukkan tidak adanya interaksi antar teknik perbanyakan bibit dan perbedaan varietas bibit terhadap diameter batang tanaman tebu.

Tabel 6. Diameter Batang Tanaman Tebu pada Umur Pengamatan 43 HST

\begin{tabular}{|c|c|c|c|c|c|c|}
\hline perlakuan & \multicolumn{7}{|c|}{ Diameter Batang } \\
\hline Varietas (V) & 8 & 15 & 22 & 29 & 36 & 43 \\
\hline V1 & $3,51 \mathrm{a}$ & $5,46 \mathrm{a}$ & $6,42 \mathrm{a}$ & $7,95 \mathrm{a}$ & $9,91 \mathrm{a}$ & $12,98 \mathrm{a}$ \\
\hline V2 & $3,0 \mathrm{a}$ & $5,19 \mathrm{a}$ & $5,54 \mathrm{a}$ & $6,75 \mathrm{a}$ & $7,76 \mathrm{a}$ & $10,18 \mathrm{a}$ \\
\hline V3 & $2,53 \mathrm{a}$ & $5,28 \mathrm{a}$ & $6,16 \mathrm{a}$ & $7,53 \mathrm{a}$ & $9,48 \mathrm{a}$ & $11,76 \mathrm{a}$ \\
\hline Teknik Perbanyakan (T) & & & & & & \\
\hline T1 & $3,03 \mathrm{a}$ & $4,92 \mathrm{a}$ & $5,59 \mathrm{a}$ & $6,7 \mathrm{ab}$ & $8,24 \mathrm{a}$ & $10,81 \mathrm{a}$ \\
\hline T2 & $3,1 \mathrm{a}$ & $5,91 \mathrm{a}$ & $7,23 \mathrm{a}$ & $9,22 \mathrm{~b}$ & $11,1 \mathrm{a}$ & $13,99 \mathrm{a}$ \\
\hline T3 & 2,92a & $5,1 \mathrm{a}$ & $5,3 \mathrm{a}$ & $6,3 \mathrm{a}$ & $7,83 \mathrm{a}$ & $10,12 \mathrm{a}$ \\
\hline
\end{tabular}

Keterangan : angka-angka yang di dampingi huruf yang sama pada kolom yang sama dinyatakan tidak berbeda nyata pada uji BNJ

\section{Jumlah anakan}

Berdasarkan hasil analisa ragam (lampiran 9) untuk jumlah anakan pada umur pengamatan 32, dan 43 HST menunjukkan tidak adanya interaksi antar teknik perbanyakan bibit dan perbedaan varietas bibit terhadap jumlah anakan tanaman tebu.

Tabel 7. Jumlah anakan tanaman tebu pada umur pengamatan 43 HST

\begin{tabular}{|c|c|c|}
\hline perlakuan & \multicolumn{2}{|c|}{ Jumlah Anakan } \\
\hline Varietas (V) & 32 & 43 \\
\hline V1 & $2,11 \mathrm{a}$ & $4,56 \mathrm{a}$ \\
\hline V2 & $1,56 \mathrm{a}$ & $2,67 \mathrm{a}$ \\
\hline V3 & $1,56 \mathrm{a}$ & $3,67 \mathrm{a}$ \\
\hline Teknik Perbanyakan (T) & & \\
\hline T1 & $1,44 \mathrm{a}$ & $3,78 \mathrm{a}$ \\
\hline T2 & $2,22 \mathrm{a}$ & $3,89 \mathrm{a}$ \\
\hline T3 & $1,56 \mathrm{a}$ & $3,22 \mathrm{a}$ \\
\hline
\end{tabular}

Keterangan : angka-angka yang di dampingi huruf yang sama pada kolom yang sama dinyatakan tidak berbeda nyata pada uji BNJ

\section{Pertunasan}

Dari hasil penelitian selama 44 hari maka dapat diketahui daya tumbuh tunas dari tiap perlakuan, beberapa perlakuan menunjukan daya tumbuh tunas $100 \%$ seperti PS 881 (V1), dan PSJK 922 (V2) yang menunjukan daya tumbuh tunas yang lebih besar dibandingkan dengan Bulu Lawang (V3) hal ini sesuai 
dengan pendapat Rokhman (2014) yang menjelaskan bahwa pertumbuhan mata tunas ditentukan oleh faktor genetik yaitu klon, dan teknik budidaya serta interaksi keduanya. Bagal cenderung lebih cepat dalam menumbuhkan tunasnya.

Hasil analisa ragam pada variabel tinggi tanaman pada menunjukan bahwa pada umur pengamatan $8,15,22,29,36$, dan 43 HST pada kombinasi perlakuan varietas (V) dan teknik pembuatan bibit (P) tidak ada beda nyata, namun pada tabel kecepatan pertumbuhan umur 16 HST nampak terdapat beda nyata pada variabel (V) dan sangat nyata pada variabel $(\mathrm{P})$.

Seperti penjelasan Rukmana (2015), bahwa teknik perbanyakan bibit tebu bagal mempunyai kelebihan, yaitu mampu tumbuh lebih cepat karena cadangan makanan tersedia lebih banyak jika dibandingkan dengan SBP atau budset, namun dalam pertumbuhannya terkadang tidak seragam.

Pada parameter jumlah daun, hasil analisa ragam menunjukan adanya beda nyata pada teknik pembuatan bibit $(\mathrm{P})$, begitu juga dengan luas daun pada berbagai umur tanaman. Adanya proses fotosintesis menghasilkan metabolit primer yang dipakai untuk metabolisme tanaman sehingga terjadi pertumbuhan dan perkembangan. Kemampuan daun untuk menghasilkan produk fotosintat ditentukan oleh produktivitas per satuan luas daun dan total luas daun. Energi yang dihasilkan sangat tergantung pada rasio ekternal dan internal daun (Fahn, 1995).

Hasil analisa ragam terlihat tidak ada beda nyata antar perlakuan varietas dan teknik perbanyakan bibit terhadap jumlah anakan tanaman tebu, hal tersebut menunjukkan bahwa tanaman tebu yang berasal dari bibit mata tunas tunggal dapat tumbuh normal seperti bibit bagal ataupun mata ruas tunggal meskipun ukuran bibit tersebut lebih kecil.

\section{KESIMPULAN DAN SARAN}

\section{Kesimpulan}

Dari hasil penelitian dan pembahasan yang telah diuraikan, dapat disimpulkan beberapa hal sebagai berikut : 
1. Tidak ada pengaruh interaksi antara perlakuan varietas $(\mathrm{V})$ dengan perlakuan teknik perbanyakan bibit (T) terhadap semua variabel yang diamati.

2. Perlakuan varietas tidak berpengaruh nyata terhadap semua variabel pengamatan.

3. Perlakuan teknik perbanyakan bibit berpengaruh nyata terhadap diameter batang (DB) pada umur pengamatan $29 \mathrm{HST}$, jumlah dan luas daun, kecepatan tumbuh pada umur pengamatan $15 \mathrm{HST}$.

4. Perlakuan teknik perbanyakan bibit berpengaruh nyata terhadap kecepatan tumbuh tunas, jumlah daun, luas daun, dan diameter tunas.

\section{Saran}

Berdasarkan hasil penelitian yang telah dilakukan perlu adanya penelitian lebih lanjut untuk mengkaji tentang pengaruh teknik pembuatan bibit. Penelitian selanjutnya dianjurkan menggunakan Rancangan Acak Lengkap, dikarenakan tidak adanya pengaruh nyata antar ulangan I, II, dan III selama masa penelitian 44 hari, artinya antara batang bawah, tengah dan atas tidak terdapat pengaruh nyata dalam kecepatan pertumbuhan mata tunas pada tanaman tebu.

Dari penelitian yang telah dilakukan selama 44 hari didapat hasil bahwa perlakuan T1 (Single Bud Planting) dan T3 (Bud Set) tidak terdapat beda nyata, maka dapat disarankan untuk melakukan pembibitan tanaman tebu dengan cara bud set dengan keunggulan dari faktor biaya yang lebih rendah dibanding dengan perbanyakan bibit menggunakan Singel Bud Planting.

\section{DAFTAR PUSTAKA}

Ciptadi, G. 2013. Tanaman Tebu. Jogja Power. Yogyakarta.

Fahn, A. 1992. Anatomi Tumbuhan. PT Gramedia. Jakarta.

Rokhman, H., T. Supriyanta. 2014. Jumlah Anakan dan Rendemen Enam Klon Tebu (Saccharum officinarum L.) Asal Bibit Bagal, Mata Ruas Tunggal, dan Mata Tunas Tunggal. Kebun Percobaan Tridarma, Fakultas Pertanian, Universitas Gadjah Mada. Yogyakarta.

Rukmana, R.H. 2015. Untung Selangit Dari Agribisnis Tebu. Lily publisher. Yogyakarta. 